\title{
A comparison of the detection of BRCA mutation carriers through the provision of Jewish population-based genetic testing compared with clinic-based genetic testing
}

\author{
K A Metcalfe ${ }^{1,2}$, A Poll $^{2}$, R Royer ${ }^{2}$, S Nanda ${ }^{2}$, M Llacuachaqui ${ }^{2}$, P Sun ${ }^{2}$ and S A Narod ${ }^{\star, 2,3}$ \\ ${ }^{1}$ Lawrence S Bloomberg Faculty of Nursing, University of Toronto, 155 College Street, Toronto, Ontario M5T 1P8, Canada; \\ ${ }^{2}$ Women's College Research Institute, 790 Bay Street, 7th floor, Toronto, Ontario M5G 1N8, Canada and ${ }^{3}$ Dalla Lana School of \\ Public Health, University of Toronto, 155 College St, 6th floor, Toronto, Ontario M5T 3M7, Canada
}

Background: Guidelines for genetic testing for BRCA1 or BRCA2 stipulate that a personal or family history of cancer is necessary to be eligible for testing. Approximately $2 \%$ of Ashkenazi Jewish women carry a mutation, but to date population-based testing has not been advocated. Little is known about the relative yield of a conventional genetic testing programme versus a programme of widespread testing in a population with common founder mutations.

Methods: We provided both referral-based and Jewish population-based testing between 2008 and 2012. We compared the numbers of BRCA mutation carriers identified through the two streams and estimated the number of genetic counselling hours devoted to each programme.

Results: From 2008 to 2012, 38 female carriers were identified through 487 referrals to our genetics centre (29 unaffected with cancer). During the same time, 6179 Jewish women were tested through our population-based programme and 93 mutation carriers were identified (92 unaffected with cancer). Fewer counsellor hours were devoted to the population-based than to the clinical referral-based testing programme.

Conclusion: Genetic testing of all Jewish women above the age of 25 years will greatly expand the number of BRCA mutation carriers identified without a commensurate increase in the number of hours required for counselling.

Genetic testing for BRCA1 and BRCA2 has been available for over 15 years. Since 1995, the eligibility criteria for genetic testing have been evolving. Presently, eligibility for genetic testing relies on personal and/or family history of breast or ovarian cancer. In some cases, a woman who is ineligible for testing will become eligible after she develops cancer. In contrast, population-based genetic testing does not restrict testing to women at an elevated risk and offers a greater opportunity to identify women at a high risk of developing cancer before diagnosis.

Two founder mutations in BRCA1 and one in BRCA2 are present in $1.2-2.5 \%$ of all Ashkenazi Jewish individuals (Roa et al,
1996; Struewing et al, 1997) and comprise the majority of deleterious BRCA mutations in the Jewish population (Kauff et al, 2002; Phelan et al, 2002). Genetic testing for the founder panel is technically straightforward and is much less expensive than conducting a full mutation screen. We have recently proposed, based on a study of over 2000 women, that population-wide genetic testing for all Jewish women is warranted (Metcalfe et al, 2010a). The approach has not been adopted and is not promoted in any of the current testing guidelines. It is not known yet to what extent the yield of population-based genetic testing compares with the yield of traditional clinical referral 
genetic testing. From 2008 to 2012, we offered genetic testing through both clinical streams at the Women's College Hospital, Toronto, and we are now in the unique position to compare the yield of the two approaches.

\section{METHODS}

All women who presented for evaluation for genetic testing for BRCA1 and BRCA2 at Women's College Hospital, Toronto between 1 May 2008 and 1 May 2012 were included in the study. Patients were either tested through the regular clinical referralbased programme or the Jewish population-based study. Ethics approval was obtained from the Women's College Hospital.

Clinical referral sample. All women who were referred to the Women's College Hospital for genetic counselling and possible testing were identified. These women met the Guidelines of the Ontario Ministry of Health for the provision of genetic testing for $B R C A 1$ or BRCA2. The family history of cancer was assessed and included the evaluation of the number and types of cancer and ages of cancer. All women received standard pre- and post-test counselling (regardless of genetic test result). Genetic testing involved complete sequencing of both BRCA1 and BRCA2 and detection of large rearrangements by multiplex ligation-dependent probe amplification. If a BRCA mutation was identified, relatives were also offered genetic testing. These subjects are included in this group as well; that is, some patients were the first in the family to have a mutation detected (proband) and some were tested on the basis of a known family mutation (secondary case).

Ashkenazi Jewish sample. During the study period, 6108 unselected Jewish women presented for population-based genetic testing (three mutations) in the context of a research study (Metcalfe et al, 2012). Pretest counselling was in the context of an information brochure. In the event when a mutation was detected, the woman was offered full genetic counselling and all first-degree female relatives over the age of 18 were offered genetic testing.

\section{RESULTS}

A total of 6421 women were tested for BRCA1 and BRCA2 mutations: 242 women were tested through the clinical genetics service (192 probands and 50 relatives) and 6179 women were tested in the Jewish population-based genetic testing study (6108 probands and 71 relatives).

Referral-based sample. Of the 437 female probands referred to the clinical cancer genetics programme, 192 (44\%) met the provincial criteria for the genetic testing for BRCA1 and BRCA2 and underwent a genetic test (Table 1). Twenty-two women

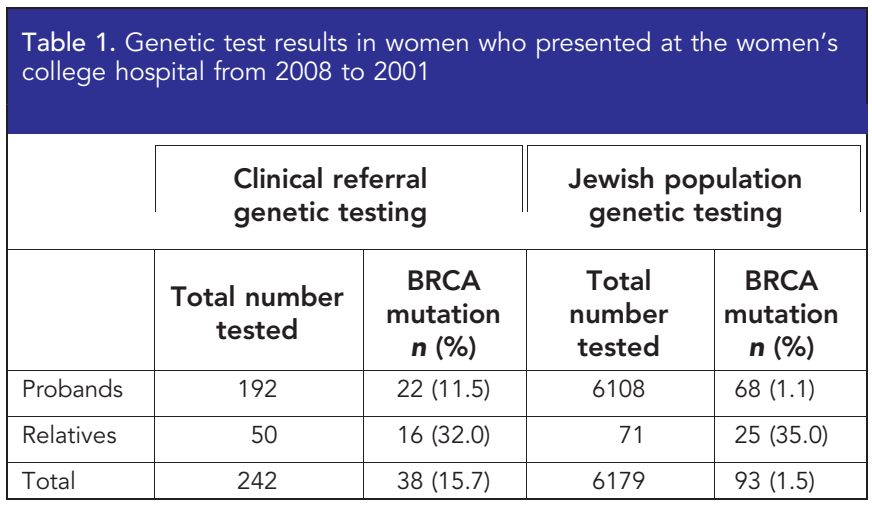

(11.5\%) were identified as having a mutation (10 in BRCA1 and 12 in BRCA2). The mean age of the women with a BRCA mutation was 46 years (range 28-71 years). Nine women (41\%) had a previous diagnosis of cancer ( 8 breast cancers and 1 ovarian cancer). A total of 50 female relatives were tested, of whom $16(32 \%)$ were positive. In summary, 487 women were referred to our clinic genetics service (including probands and relatives), of whom 242 women underwent genetic testing and 38 women (15.7\%) were identified with a BRCA mutation.

Population-based Jewish sample. Sixty-eight of 6108 probands (1.1\%) were found to have a BRCA mutation (25 in BRCA1 and 43 in $B R C A 2$ ). The mean age of these women was 44.2 years (range 24-68 years). None had a previous diagnosis of breast cancer or ovarian cancer. On the basis of the Ontario Ministry of Health Guidelines for BRCA genetic testing, 26 of these women (38.2\%) would have qualified for genetic testing. Seventy-one female relatives presented for testing. Of these 71 female relatives, 25 $(35.2 \%)$ were found to have a BRCA mutation. In summary, as a result of Jewish population genetic testing, 6179 women received genetic testing for the three common Jewish founder mutations (including probands and relatives), and 93 women (1.5\%) were identified as having a BRCA mutation. Of those, 92 women $(98.9 \%)$ were unaffected (Table 2). Pretest genetic counselling was not offered; however, if the woman was identified with a mutation, a 90 -min post-test genetic counselling session was provided. This resulted in a $102 \mathrm{~h}$ of genetic counselling. All the 71 relatives were provided with a $1 \mathrm{~h}$ each of pre- and post-genetic testing counselling sessions, resulting in $142 \mathrm{~h}$ of counselling. The total amount of time provided by genetic counsellors for Jewish

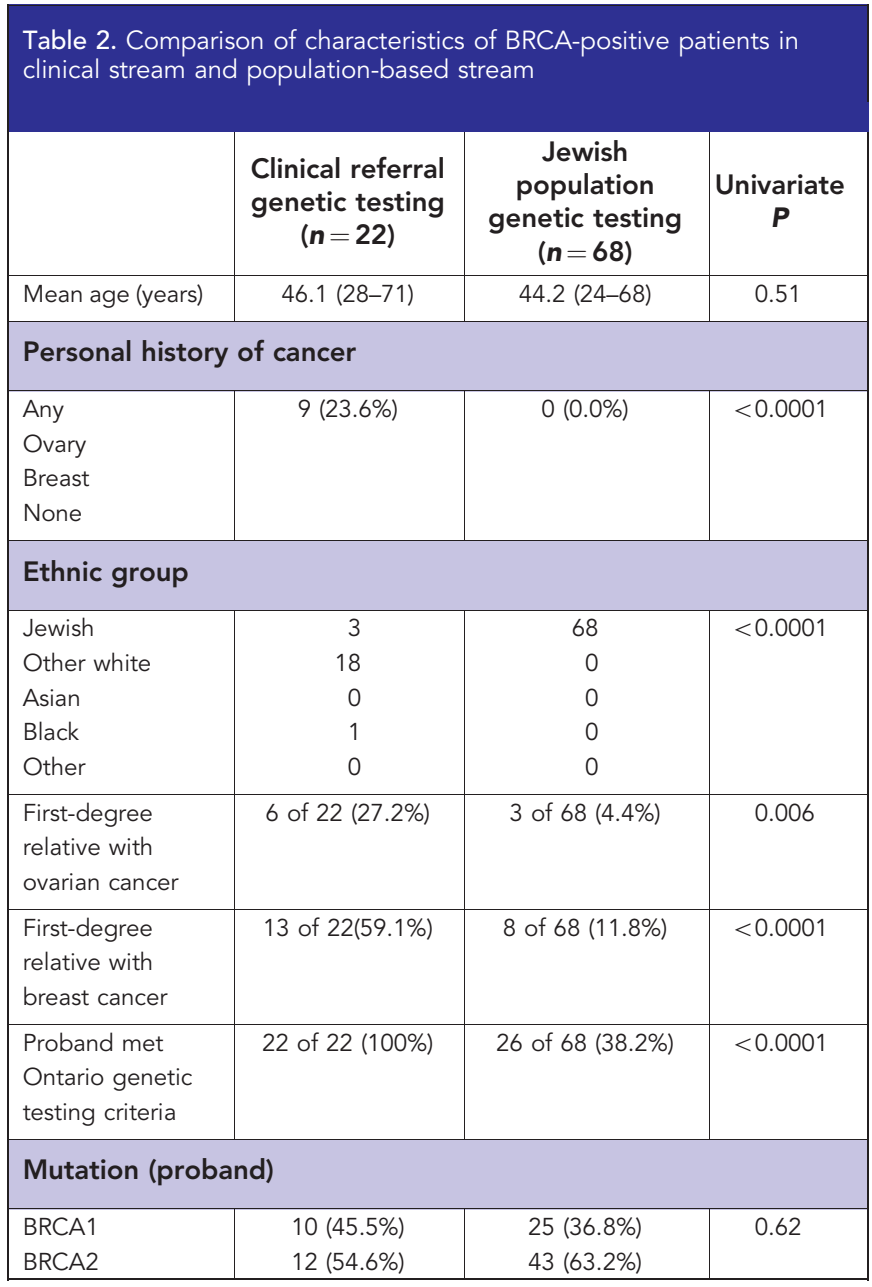


population genetic testing was $244 \mathrm{~h}$ (2.6 h per BRCA-positive result) compared with $484 \mathrm{~h}$ of genetic counselling in order to identify 38 carriers in the regular clinical stream $(12.7 \mathrm{~h}$ per positive BRCA result).

\section{DISCUSSION}

Our results provide further justification that genetic testing for BRCA1 and BRCA2 mutations should be offered to all Jewish women, regardless of personal or family history of cancer. Over a 4-year period, we identified far more unaffected women with a BRCA1 or BRCA2 mutation $(n=92)$ through a genetic testing programme that targeted all Jewish women than we did through a conventional, referral-based programme $(n=29)$, despite the fact that the population-based approach was less resource intensive. The Ontario genetic testing criteria were established under the assumption that a woman should have a risk of $10 \%$ or greater for carrying a BRCA mutation for testing to be warranted. However, not all women with a mutation meet this standard and many carriers will be missed. The US National Comprehensive Cancer Network (NCCN, 2012) has guidelines for genetic testing for hereditary breast and/or ovarian cancer. In Jewish individuals without breast or ovarian cancer, the guidelines specify that a close family member must have breast or ovarian cancer. In our study, only $38 \%$ of the Jewish BRCA mutation carriers qualified for genetic testing (Metcalfe et al, 2010b). Many women who are at high risk of developing breast and ovarian cancer are not being identified because of our historical reliance on personal and family history of cancer. Moreover, many women who do meet the criteria for testing are not identified as such by their health-care providers (Metcalfe et al, 2009). In the current study, 38\% of the women identified as having a BRCA mutation would have qualified for genetic testing, but they were either unaware of the recommendation or had not been referred by their health-care provider.

Our goal of population-based Jewish genetic testing is to identify unaffected women at risk of developing cancer, so they may pursue risk reduction options and intensive cancer screening. However, with traditional genetic testing for $B R C A 1$ and $B R C A 2$, we rely on the diagnosis of cancer in order to identify a high-risk individual or family. In the clinical sample, $41 \%$ of the probands identified with a BRCA mutation had a previous diagnosis of cancer compared with none of the women in the population-based Jewish sample with a $B R C A 1$ or $B R C A 2$ mutation. We are in a better position to reduce the numbers of new cancers in carriers identified by population genetic testing in the Jewish population than through conventional clinical genetic testing. We have previously reported that women who are identified with a BRCA mutation through the provision of population genetic testing elect for cancer risk reduction options at similar levels to that of women identified in a clinical population (Metcalfe et al, 2012). Within 2 years of receiving a positive BRCA result through the unselected Jewish study, $11.1 \%$ of women underwent prophylactic mastectomy, and $89.5 \%$ underwent a prophylactic salpingo-oophorectomy. We have also reported that Jewish population genetic testing does not cause long-term psychosocial distress (Metcalfe et al, 2012). Bosch et al (2012) suggest that we should aim to 'demystify' the presumed negative effect on psychosocial functioning in order to increase the number of individuals who elect for genetic testing. In conclusion, the data in this paper further support the position for offering genetic testing to all Jewish women. It is hoped that in the future, the cost of genetic testing will be sufficiently low and that such testing might be extended to non-Jewish women as well.

\section{ACKNOWLEDGEMENTS}

This research was supported by Maj for Mammaries and the Canadian Breast Cancer Research Alliance. We thank Lisa Priest for her continued interest; all women who participated in the study for their enthusiasm; DNA Genotek for their donation of the Oragene kits; and all of the volunteers, including Ilana Horvath and Anneli Loo, who helped in making this study possible.

\section{REFERENCES}

Bosch N, Junyent N, Gadea N, Brunet J, Ramon Y, Cajal T, Torres A, Graña B, Velasco A, Darder E, Mensa I, Balmaña J (2012) What factors may influence psychological well being at three months and one year post BRCA genetic result disclosure? Breast 21: 755-760.

Kauff ND, Perez-Segura P, Robson ME, Scheuer L, Siegel B, Schluger A, Rapaport B, Frank TS, Nafa K, Ellis NA, Parmigiani G, Offit K (2002) Incidence of non-founder BRCA1 and BRCA2 mutations in high risk Ashkenazi breast and ovarian cancer families. J Med Genet 39: 611-614.

Metcalfe KA, Fan I, McLaughlin J, Risch HA, Rosen B, Murphy J, Bradley L, Armel S, Sun P, Narod SA (2009) Uptake of clinical genetic testing for ovarian cancer in Ontario: a population-based study. Gynecol Oncol 112: 68-72.

Metcalfe KA, Mian N, Enmore M, Poll A, Llacuachaqui M, Nanda S, Sun P, Hughes KS, Narod SA (2012) Long-term follow-up of Jewish women with a BRCA1 and BRCA2 mutation who underwent population genetic screening. Breast Cancer Res Treat 133: 735-740.

Metcalfe KA, Poll A, Llacuachaqui M, Nanda S, Tulman A, Mian N, Sun P, Narod SA (2010a) Patient satisfaction and cancer-related distress among unselected Jewish women undergoing genetic testing for BRCA1 and BRCA2. Clin Genet 78: 411-417.

Metcalfe KA, Poll A, Royer R, Llacuachaqui M, Tulman A, Sun P, Narod SA (2010b) Screening for founder mutations in BRCA1 and BRCA2 in unselected Jewish women. J Clin Oncol 28: 387-391.

NCCN (2012) NCCN Clinical Practice Guidelines in Oncology: Genetic/ Familial High-Risk Assessment: Breast and Ovarian, Vol. 2012. National Comprehensive Cancer Network.

Phelan CM, Kwan E, Jack E, Li S, Morgan C, Aube J, Hanna D, Narod SA (2002) A low frequency of non-founder BRCA1 mutations in Ashkenazi Jewish breast-ovarian cancer families. Hum Mutat 20: 352-357.

Roa BB, Boyd AA, Vocik K, Richards CS (1996) Ashkenazi Jewish population frequencies for common mutations in BRCA1 and BRCA2. Nat Genet 14: 185-187.

Struewing JP, Hartge P, Wacholder S, Baker SM, Berlin M, McAdams M, Timmerman MM, Brody LC, Tucker MA (1997) The risk of cancer associated with specific mutations of BRCA1 and BRCA2 among Ashkenazi Jews. N Engl J Med 336: 1401-1408.

This work is published under the standard license to publish agreement. After 12 months the work will become freely available and the license terms will switch to a Creative Commons AttributionNonCommercial-Share Alike 3.0 Unported License. 